\title{
B-TUD-1: a versatile mesoporous catalyst $\uparrow$
}

Cite this: RSC Adv., 2013, 3, 21524

Received 15th August 2013

Accepted 23rd August 2013

DOI: $10.1039 / c 3 r a 44406 f$

www.rsc.org/advances

\author{
Adeline Ranoux, Kristina Djanashvili, Isabel W. C. E. Arends and Ulf Hanefeld*
}

Novel amorphous mesoporous borosilicate, B-TUD-1, was prepared to test its performance for different sustainable reactions. The structure of the material, the effective incorporation of boron into the framework as well as the nature of incorporated boron were verified by $\mathrm{N}_{2}$-sorption, XRD, ICP-OES, TEM, $\mathrm{NH}_{3}$-desorption, MAS NMR and FTIR. The potential of these materials as catalysts was tested in two reactions under different conditions. They showed an apparently good activity and recycling potential for HMF (5-hydroxymethyl-furfural) synthesis. However leaching of boron occurred during this aqueous reaction. We could demonstrate that the leached boron was actually the catalyst of the reaction. In a second reaction, this time in organic solvent, the B-TUD-1 materials were tested for the Prins cyclisation of citronellal. A very promising activity was obtained. The catalyst could be recycled and no boron leached, as demonstrated by hot filtration experiments.

\section{Introduction}

Heterogeneous catalysts were widely studied during the last few years, in particular for the development of sustainable processes. Indeed, while representing powerful catalysts, they have the additional advantage that they are easily recyclable and thus lead to significant reductions of waste. In this context, TUD-1 materials were developed.

The special properties of mesoporous TUD-1, such as its three dimensional pore structure with a good accessibility for substrates and products, tuneable pore properties, ${ }^{\mathbf{1 , 2}}$ and a costeffective one-pot, surfactant-free synthesis by the sol-gel method, have made it a versatile heterogeneous catalyst for many interesting synthesis applications. ${ }^{3}$ TUD-1 has been successfully functionalized with numerous incorporated metals (Al, Ti, Co, Fe, V, Cr, Mo, Hf, Ga, Ni, Mn, Zr and Cu) aiming at a variety of catalytic properties. ${ }^{\mathbf{4 - 2 9}}$ Surprisingly, the incorporation of $\mathrm{B}$, in the same group as $\mathrm{Al}$, was never investigated.

Boron derivatives have proven to be efficient catalysts for a large range of reactions (reduction, Diels-Alder, aldol reactions). ${ }^{30,31}$ Boric acid itself is a good Lewis acid for esterifications, ${ }^{32}$ amidifications ${ }^{33}$ and dehydrations of polyols..$^{34-36}$

Both TUD-1 materials and boric acid have been demonstrated as excellent catalysts for sustainable reactions, conversion of renewable materials and synthesis of platform chemicals (for example, boric acid catalysed synthesis of $\mathrm{HMF}^{37}$ or Hf-TUD-1 catalysed conversion of glycerol to solketal). ${ }^{\mathbf{1 4}}$

Technische Universiteit Delft, Department of Biotechnology, Gebouw voor Scheikunde, Julianalaan 136, 2628 BL Delft, The Netherlands. E-mail: u.hanefeld@tudelft.nl; Fax: +31(0) 152781415

† Electronic supplementary information (ESI) available. See DOI: $10.1039 / \mathrm{c} 3 \mathrm{ra} 44406 \mathrm{f}$
Previously other boron-incorporated zeolites and mesoporous materials (Beta- and ZSM-5 zeolites, SBA-15, MCM-41) ${ }^{38-49}$ have been reported. Key examples are the B-MCM-41-catalysed Beckmann rearrangement of cyclohexanone oxime ${ }^{\mathbf{4}}$ permitting the efficient synthesis of caprolactam, and, the B-MCM-41-catalysed three component Strecker reaction also leading to the formation of $\alpha$-aminonitriles, ${ }^{50}$ intermediates for the synthesis of $\alpha$-aminoacids or N-containing heterocycles. Boron is herewith a promising, cheap and environmentally benign element that imparts activity to mesoporous materials. In this paper a novel approach towards the synthesis of heterogeneous mesoporous B-catalyst is presented, B-TUD-1. Combining the advantageous properties of the TUD-1 materials (notably their 3D structure suppressing diffusion limitation of the substrates) and excellent catalysis efficiency of the boron derivatives, the obtained B-TUD- 1 catalysts should present new versatile catalytic properties. We present here not only the preparation of the catalyst and its full characterization, and additionally performance tests for two important, sustainable reactions, the HMF synthesis, and, the Prins cyclisation of citronellal.

\section{Results and discussion}

Preparation of the material

The M-TUD-1 materials (Al and B) were prepared by the sol-gel method using triethanolamine as a complexing agent following the protocols described earlier. ${ }^{9}$ The $\mathrm{M}$ was included in the form of the isopropoxide $\mathrm{M}(i \mathrm{PrO})_{3}$.

The use of triethanolamine permits to avoid the use of any surfactants or liquid crystal templates. Complexing with the metal triethanolamine leads to the formation of the mesopores (Fig. 1). Initially the active metal is complexed to form an atrane. ${ }^{51,52}$ Then these atranes complex together with free triethanolamine creating the framework of the material. During 
A)

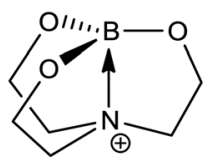

Fig. 1 Atranes complexes, triethanolamine as (A) metal complexing agent and (B) templating agent.

gelation and also after calcination and consequent removal of organic compounds, the metal is incorporated into the framework of the material as oxide species. ${ }^{3,4}$ This is also known as the atrane route. ${ }^{53}$ The formation of the boratranes has been demonstrated as to be a set of complex equilibria between the different coordination forms. Several stable boratranes with three six-membered rings where the boron has a tetrahedral structure could be characterised. ${ }^{54-56}$ Another interesting point is that by the use of a similar method introducing surfactants, ordered mesoporous materials could be obtained (for example SBA-15 ${ }^{57}$ ) in contrast to the amorphous, mesoporous TUD-1 materials.

Different ratios of $\mathrm{M}$ were introduced, Si/Al 25 (Al-TUD-1 25), and Si/B 50, 25 and 10 (B-TUD-1 50, 25 and 10 resp.). A hydrothermal treatment of $6 \mathrm{~h}$ at $180{ }^{\circ} \mathrm{C}$ was applied that has defined the size of the pores and the mesoporous structure. ${ }^{1}$ Subsequent calcination at $600{ }^{\circ} \mathrm{C}$ for 10 hours led to the final material.

\section{Characterization: a classical mesoporous catalyst}

The ratio of incorporated boron was verified by elemental analysis by inductively coupled plasma atomic emission spectroscopy (ICP-OES). The mesoporous character of the materials was confirmed by X-ray diffraction (XRD), $\mathrm{N}_{2}$ sorption and highresolution transmission electron micrographs (TEM). The acid sites were characterised by temperature-programmed desorption of $\mathrm{NH}_{3}$. Finally, the incorporation of boron was verified by XRD at small angles and by MAS NMR. The latter permitted also to characterise the nature of the boron species incorporated into the mesoporous framework.

Results of the elemental analysis (ICP-OES) and the porosity measurements are given in Table 1 . The elemental analysis reveals $\mathrm{Si} / \mathrm{B}$ ratios of the calcined catalysts very close to the actual added amount. $\geq 95 \%$ of the added boron compounds

Table 1 Physico-chemical characterization of M-TUD-1 with different Al or B loadings

\begin{tabular}{|c|c|c|c|c|}
\hline \multirow{2}{*}{$\begin{array}{l}\text { Catalyst } \\
\text { Si/X gel }\end{array}$} & \multirow{2}{*}{$\begin{array}{l}\text { Al-TUD-1 } \\
25\end{array}$} & \multicolumn{3}{|c|}{ B-TUD-1 } \\
\hline & & 50 & 25 & 10 \\
\hline $\mathrm{Si} / \mathrm{X}$ product & $26^{a}$ & $54^{a}$ & $26^{a}$ & $11^{a}$ \\
\hline$S_{\mathrm{BET}}\left(\mathrm{m}^{2} \mathrm{~g}^{-1}\right)$ & 850 & 428 & 532 & 637 \\
\hline Pore diameter $D_{\text {pore }}(\mathrm{nm})$ & 3.6 & 8.5 & 5.9 & 5.2 \\
\hline Total volume pore $V_{\text {pore }}\left(\mathrm{mL} \mathrm{g}^{-1}\right)$ & 0.7539 & 0.883 & 0.784 & 0.831 \\
\hline Micropore volume $V_{\text {micro }}\left(\mathrm{mL} \mathrm{g}^{-1}\right)$ & n.d. ${ }^{b}$ & 0.0075 & 0.035 & 0.027 \\
\hline
\end{tabular}

during the preparation of the gel was incorporated. This demonstrates the good predictability of the preparation method, already observed with other M-TUD-1 materials. ${ }^{\mathbf{8} 58}$

According to Jansen et al., ${ }^{\mathbf{1 , 2}}$ the pore size of TUD-1 material is tuneable and can be controlled by the time of the hydrothermal treatment. After a treatment of $6 \mathrm{~h}$, the expected average pore size was between 6 and $8 \mathrm{~nm}$. The measured pore diameters correspond to the theoretical values and are slightly larger than those for classical M-TUD-1 (average around $4.0 \mathrm{~nm})^{3}$ and close to other boron containing mesoporous silicates (for example, B-MCM-41, average around $4.5 \mathrm{~nm}$, B-SBA15 , average around $6.5 \mathrm{~nm}) .^{\mathbf{4 3 , 4 6 , 4 7}}$ The surface area of B-TUD-1 increases upon increasing of the metal loading. At the same time, the average pore diameter decreases in line with the results for other M-TUD- 1 materials ${ }^{3}$ and the boron substituted mesoporous SBA-15. ${ }^{43}$

The $\mathrm{N}_{2}$ adsorption and desorption isotherms of the B-TUD-1 50 and 25 (Fig. 2) reveal a typical "type IV" hysteresis loop, with a large uptake of nitrogen at relative pressures between 0.5 and 0.9 due to capillary condensation in the mesopores. A plateau at relative pressures of above $0.9 p / p_{0}$ indicates the absence of large mesopores or macropores. The B-TUD-1 10 isotherm (Fig. 2) differs slightly by the fact that it shows a lower uptake in the first phase, possibly related to a lower mesoporosity. The material has the lowest pore diameter and micropore volume (Table 1). This might result from the intensified interaction of the $\mathrm{B}$ atoms with the silica structure as it has been observed for the Zr-TUD-1 material. ${ }^{58}$

The X-ray diffractograms of the materials (Fig. 3) show a broad intense peak at low angles around $0.5-12 \theta^{\circ}$ in line with the mesostructured character of these materials. No correlation could be established between the peak intensity and the Si/B ratio.

The complete XRD spectra of B-TUD-1 10, 25 and 50, as well as that of Al-TUD-1 25 for comparison, were recorded. No crystalline structure was observed in any case. A spectrum of boric acid was measured as a reference (multiple peaks, characteristic of this crystalline product). None of the characteristic signals of boric acid could be detected in the B-TUD-1 spectra, not even at a $\mathrm{Si} / \mathrm{B}$ ratio of 10 . This is quite remarkable compared to other M-TUD-1 materials. It indicates a complete framework incorporation even at the highest metal loading, where most of

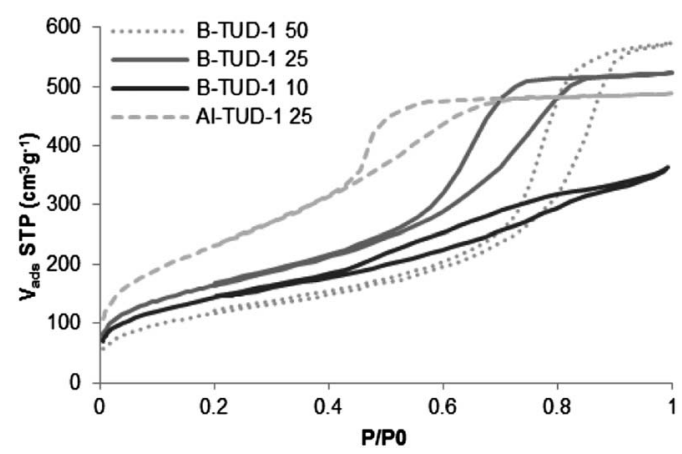

Fig. $2 \mathrm{~N}_{2}$ adsorption and desorption isotherms at $77 \mathrm{~K}$. 

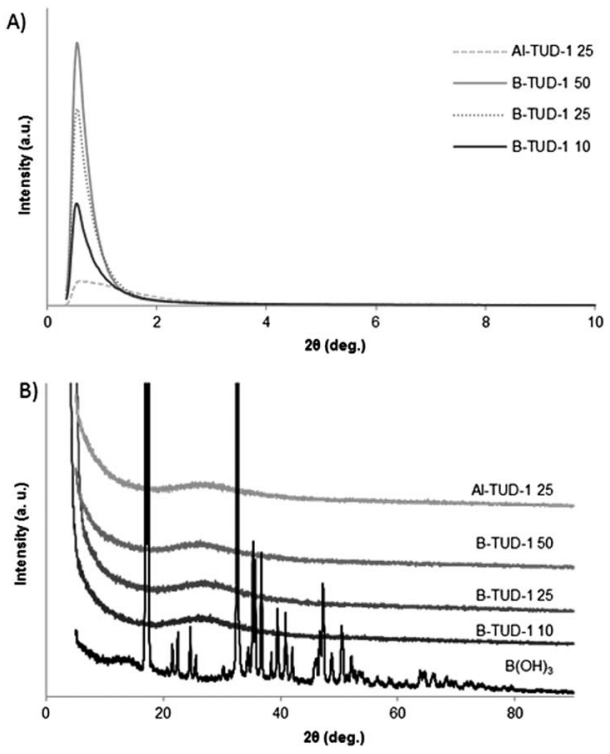

Fig. 3 Powder XRD diffraction patterns of calcined B-TUD-1 (A) at small angles (0.5 to 10 deg.); (B) at higher angles (4 to 90 deg.).

the M-TUD-1's contain a certain percentage of metal oxides visible on TEM pictures. ${ }^{3,8}$ Complete boron incorporation at high loading has also been reported for other boron-containing zeolites $^{38,45}$ or mesoporous silicates. ${ }^{43,44}$

The TEM pictures (Fig. 4) show "worm/sponge-like" structures typical for amorphous material and TUD-1 samples., ${ }^{1,3}$ This confirms the mesoporous structure of the material. Furthermore, no crystalline boron particles could be observed even at higher loading confirming the incorporation of the boron species. Therefore, the material appeared completely amorphous, as no ordered pores or channels were visible, and as no boron (or aluminium) oxide could be detected (Fig. 3 and 4).

A temperature-programmed desorption (TPD) profile (from 100 to $500{ }^{\circ} \mathrm{C}$ ) of ammonia for different B- and Al-TUD-1 samples (Fig. 5) was measured. For all the boron-incorporated materials two peaks were observed, an intense peak at $150{ }^{\circ} \mathrm{C}$ corresponding to weak acids, and a broad peak with low intensity at around $400-500{ }^{\circ} \mathrm{C}$, corresponding to strong acid sites (Table 2). The medium acid sites (temperature around $250-300{ }^{\circ} \mathrm{C}$ ) are hardly present. The intensity of the peaks (especially for the weak acid sites) increases with the B loading (i.e. decreasing $\mathrm{Si} / \mathrm{B}$ ratio) as well as the total acidity. In the case of Al-TUD-1 25, we could observe one broad band from 100 to $350{ }^{\circ} \mathrm{C}$ corresponding to weak and medium acids, more classically observed with M-TUD-1 catalysts. ${ }^{11}$

The solid-state ${ }^{11}$ B MAS NMR (Fig. 6) showed three main peaks for the B-TUD-1 samples, corresponding to the earlier results for the boron containing mesoporous silicates as MCM-41 (ref. 42) or SBA-15 (ref. 43) (and to the results obtained for many zeolites ${ }^{39,40,49}$ ). The first peak at around $-22.9 \mathrm{ppm}$, sharp and narrow, corresponds to the 4-coordinated tetrahedral boron (mainly, 2-coordinated also possible ${ }^{43}$ symmetric form). The two other broader bands from $-11.5 \mathrm{ppm}$ to $-2.5 \mathrm{ppm}$ correspond to different trigonal

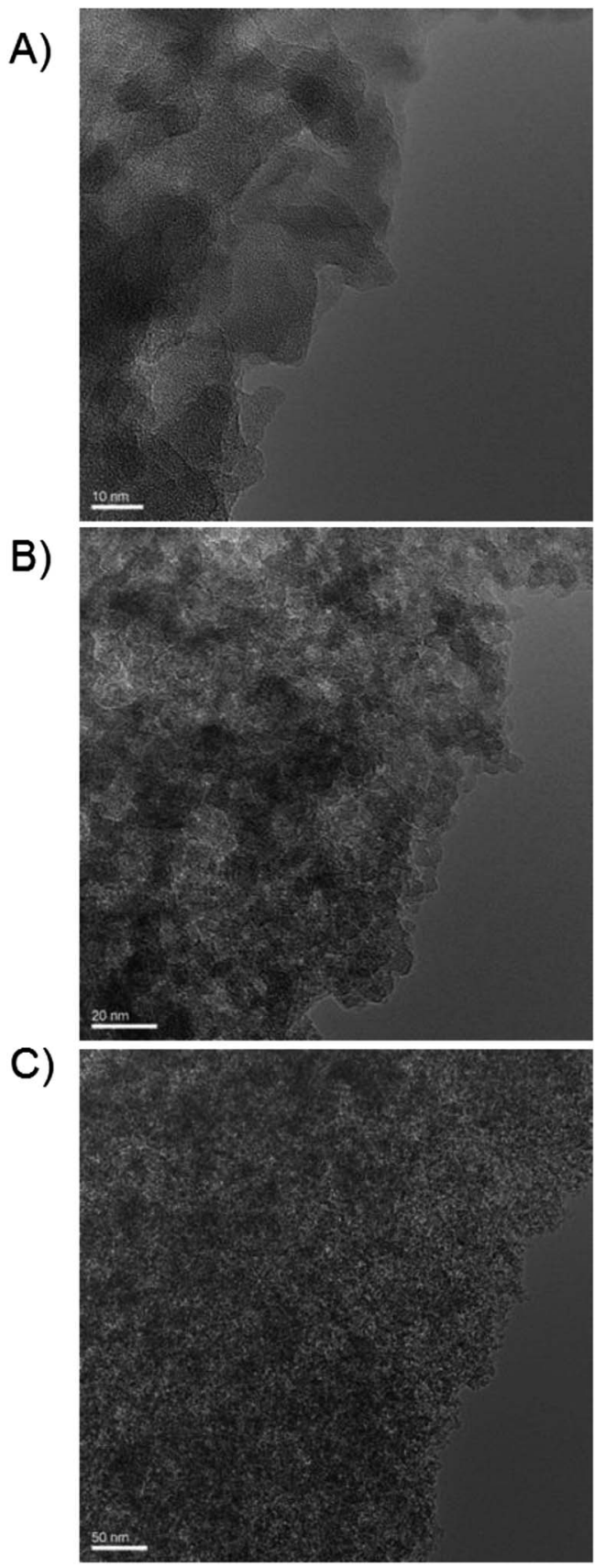

Fig. 4 TEM pictures of B-TUD-1 10 revealing the mesostructure of the catalysts (scale in nm) (A) $10 \mathrm{~nm}$, (B) $20 \mathrm{~nm}$, (C) $50 \mathrm{~nm}$.

forms of boron species with different degrees of coordination to silica (in line with literature ${ }^{39,40,42,49}$ ), namely 3 -coordinated (11.5 ppm), and trigonal B with a lower coordination number (structures in Fig. 7). With a decrease in boron loading, i.e. higher $\mathrm{Si} / \mathrm{B}$ ratio, relatively more tetrahedral boron is observed. It is however important to notice the dynamic nature of these incorporated boron species. Diverse equilibria are established between the different species, especially between tetrahedral and trigonal forms, as function of the temperature and media (hydration, presence of cations), ${ }^{45,49}$ explaining the indistinguishable broad peaks observed in the NMR spectra. 


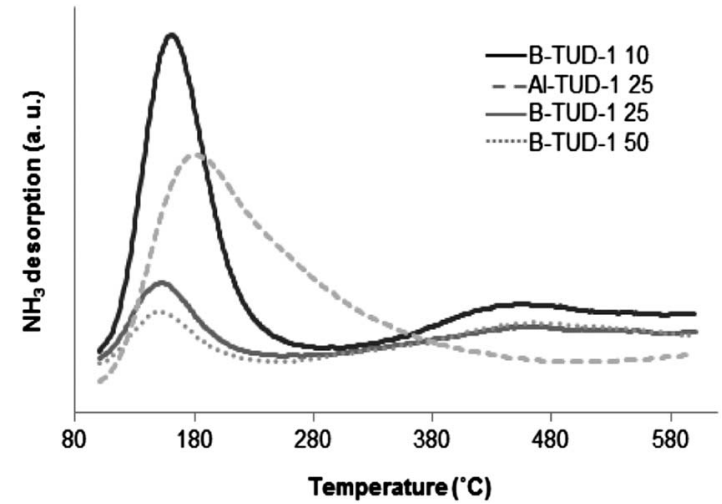

Fig. 5 Temperature-programmed desorption (TPD) profile of ammonia for various Al- and B-TUD-1 samples.

Table 2 Acidity derived from temperature-programmed desorption (TPD) of ammonia for Al-and B-TUD-1 samples with different Si/M ratios

\begin{tabular}{lllc}
\hline Catalyst & $\begin{array}{l}\text { Total acidity } \\
\left(\mathrm{mmol} \mathrm{NH}_{3} \mathrm{~g}^{-1}\right)\end{array}$ & $\begin{array}{l}\text { Temp } \\
\left({ }^{\circ} \mathrm{C}\right)\end{array}$ & $\begin{array}{l}\text { Quantity } \\
\left(\mu \mathrm{mol} \mathrm{NH} \mathrm{g}^{-1}\right)\end{array}$ \\
\hline \multirow{2}{*}{ B-TUD-1 Si/B 10/1 } & \multirow{2}{*}{0.428} & 161 & 273.3 \\
& & 295 & 0.9 \\
& & 459 & 152.4 \\
B-TUD-1 Si/B 25/1 & 0.195 & 152 & 71.7 \\
& & 473 & 115.8 \\
B-TUD-1 Si/B 50/1 & 0.147 & 148 & 35.9 \\
& & & 107.9 \\
Al-TUD-1 Si/Al 25/1 & 0.372 & $179(\max )$ & 372 \\
& & &
\end{tabular}

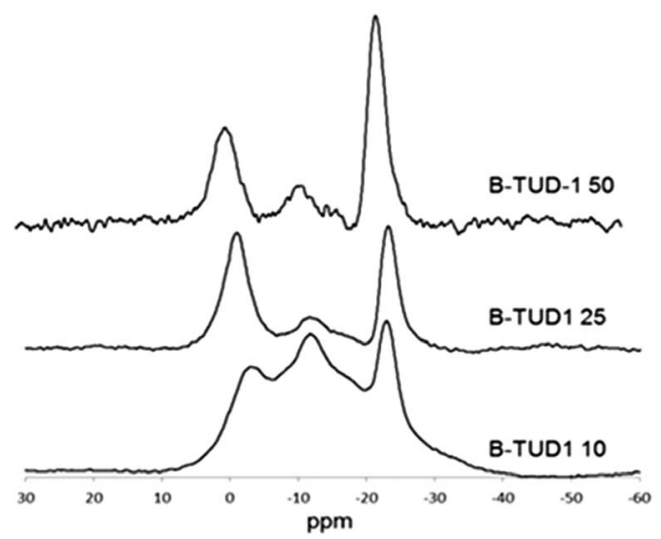

Fig. $6{ }^{11} \mathrm{~B}$ MAS NMR of B-TUD-1 catalysts $(25,10)$ referenced to $0.1 \mathrm{M}$ aq. $\mathrm{B}(\mathrm{OH})_{3}$ (most of the cited articles use $\mathrm{BF}_{3}(\mathrm{OEt})_{2}$ as reference leading to a shift of the signals of $19.8 \mathrm{ppm}$ ).

For this reason, the nature of the acid sites is also dynamic. Due to this dynamic equilibrium that is also influenced by water, it is not meaningful to determine the ratio of Lewis to Brønsted acid sites as this is dynamic too. Furthermore, the ${ }^{27} \mathrm{Al}$ MAS NMR spectrum of the Al-TUD-1 material was also measured ( $c f$. ESI; Fig. S1 $\dagger$ ). Two main peaks were observed at 0 and $55 \mathrm{ppm}$, corresponding to the octa- and tetrahedral aluminium resp., as described in the literature. ${ }^{59-61}$
The presence of tetrahedral boron species in B-TUD-1 materials was confirmed by FTIR as a shoulder at $920-930 \mathrm{~cm}^{-1}$ (mainly visible for B-TUD-1 10, Fig. 8). Another peak characteristic for the presence of trigonal boron can be identified at $1395 \mathrm{~cm}^{-1}$. $^{43,47}$

The intensity of these two peaks, related to the presence of B, decreases in line with the B loading. For comparison, these peaks are absent in the spectra of Al-TUD-1. The absorption bands at 460,810 and 1070 with a shoulder at $1200 \mathrm{~cm}^{-1}$, present in all the B- and Al-TUD-1, can be assigned to the symmetric and asymmetric stretching of $\mathrm{Si}-\mathrm{O}-\mathrm{Si}$ vibrations of tetrahedral $\mathrm{SiO}_{2}$ units (Fig. 8). Based on these results, we can postulate that B-TUD-1 materials with fully framework incorporated boron were prepared. They contain trigonal boron representing Lewis acidity as well as tetrahedral boron representing Brønsted acidity (Fig. 6 and 7) in a dynamic equilibrium.

\section{Performance test in aqueous or biphasic media: HMF synthesis}

HMF, 5-hydroxymethylfurfural, is a biobased platform chemical, obtained from sugars, especially fructose, by acid-catalysed dehydration (Scheme 1). ${ }^{62}$ However, despite the many studies that have been reported, no real efficient, sustainable and scalable route has been proposed yet. ${ }^{62}$

Many Lewis acids, ${ }^{63,64}$ zeolites and mesoporous materials ${ }^{15,22,65-70}$ were used as catalysts for this reaction. Because of the numerous advantages (recyclability, easy separation of the product, no corrosion of equipment), heterogeneous catalysts in general have been the main focus.

As Al-TUD-1 ${ }^{60}$ and boric acid ${ }^{37,71}$ were already successfully tested for HMF synthesis in biphasic systems or ionic liquids, B-TUD-1 materials appear to be promising heterogeneous, thus potentially recyclable, catalysts for HMF production. Indeed, highly stable, TUD-1 materials have been shown to be easily recovered and recycled after reaction by a calcination similar to the one used during the preparation. ${ }^{3}$

The synthesis of HMF in aqueous media is a challenging reaction. The B-TUD-1 catalysts showed very good activity for this reaction, especially under biphasic conditions with toluene.

In Fig. 9, experimental results are presented. With the B-TUD-1 catalysts under purely aqueous conditions, the conversion and yield appeared limited (same results at $150{ }^{\circ} \mathrm{C}$ for $90 \mathrm{~min}$ or $4 \mathrm{~h}, \leq 20 \%$ yield); whereas in biphasic media, at $150{ }^{\circ} \mathrm{C}$ for $4 \mathrm{~h}, 65$ to $70 \%$ conversion of fructose was observed with a yield between 40 and $45 \%$. Interestingly, these results were similar for all $\mathrm{Si} / \mathrm{B}$ ratios and very close to what can be obtained under similar conditions with Al-TUD- $1 .^{60}$

Recycling experiments were successfully carried out in biphasic media (Fig. 10). At $190^{\circ} \mathrm{C}$ up to $90 \%$ conversion, a yield of $60 \%$ can be reached after 40 minutes. This can be repeated in three consecutive cycles.

In the same way, consecutive recycling experiments were carried out in a purely aqueous phase (Fig. 11A). However, the liquid ${ }^{11} \mathrm{~B}$ NMR analysis of the reaction media revealed the presence of a broad peak at $0 \mathrm{ppm}$, corresponding to the presence of boric acid. Furthermore, the elemental analysis of the 
<smiles>C[Si](C)(C)O[B-](O)(O)O[Si](C)(C)C</smiles><smiles>C[Si](C)(C)O[B-](O)(O)O[Si](C)(C)C</smiles><smiles>C[Si](C)(C)O[B-](O)(O[Si](C)(C)C)O[Si](C)(C)C</smiles><smiles>C[Si](C)(C)O[B-](O)(O[Si](C)(C)C)O[Si](C)(C)C</smiles>

Tetrahedral Boron, Brønsted acidity<smiles>C[Si](C)(C)OB(O)O[Si](C)(C)OB(O[Si](C)(C)C)O[Si](C)(C)OB(O)O[Si](C)(C)C</smiles>

Trigonal Boron, Lewis acidity

Fig. 7 Possible tetrahedral and trigonal structures of boron incorporated in TUD-1 framework.

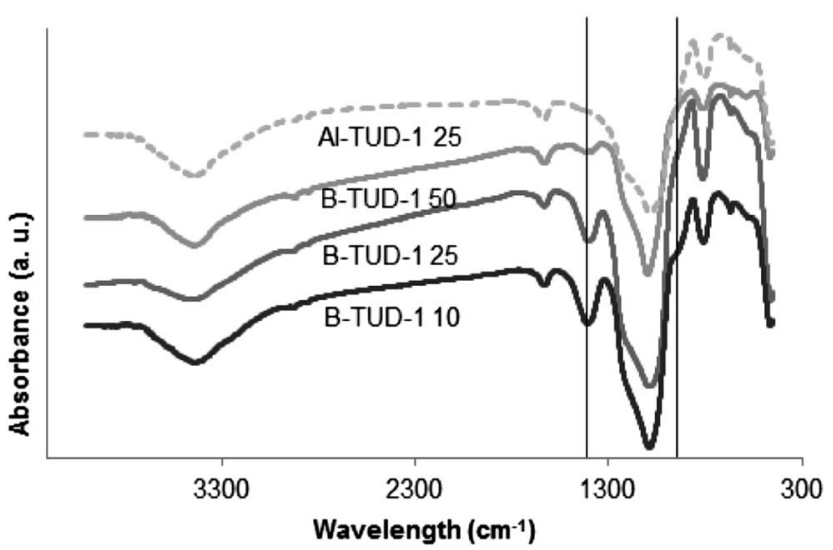

Fig. 8 FTIR spectra of B-TUD-1 50, 25, 10 and Al-TUD-1 25

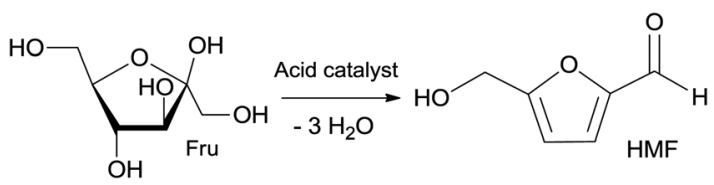

Scheme 1 Acid-catalysed dehydration of fructose (Fru) leading to the formation of HMF.

recycled catalysts after one, two or three reactions revealed an increasing $\mathrm{Si} / \mathrm{B}$ ratio (from 25 to 85 after 3 reactions, Fig. 11B), thus a decreasing $\mathrm{B}$ content on the mesoporous material. The $\mathrm{B}$ is probably slowly released during the reaction. Furthermore, a porosity analysis of the used catalysts after calcination showed a clear change in their mesoporous structure (Table 3 ). Notably a net decrease of the mesoporous surface and pore volume could be observed. The structure is probably affected by the release of $\mathrm{B}$ and the hydrolysis of the Si-O-B bonds. Finally, a ${ }^{11} \mathrm{~B}$ MAS NMR of the used catalysts ( $c f$. ESI; Fig. S2 $\dagger$ ) showed a net decrease of the peaks corresponding to tetrahedral 4-coordinated B (sharp peak at $-22.9 \mathrm{ppm}$ ), but also to the trigonal 3-coordinated $\mathrm{B}$ (broad peak at $-\mathbf{1 1 . 5} \mathrm{ppm}$ ). We observed thus under acidic conditions, in line with literature descriptions in the case of
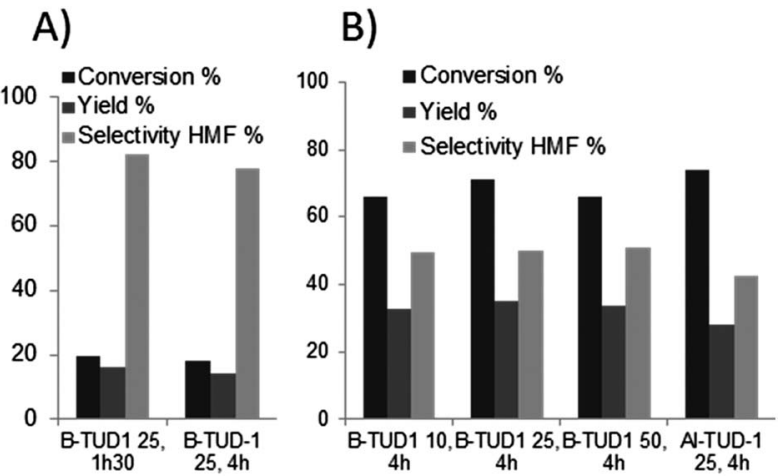

Fig. 9 B or Al-TUD-1 catalyzed HMF synthesis in (A) aqueous or (B) biphasic conditions (at $150{ }^{\circ} \mathrm{C}, 30 \mathrm{wt} \%$ fructose, $10 \mathrm{wt} \% \mathrm{M}$-TUD-1, toluene/water $3 / 1$ ).

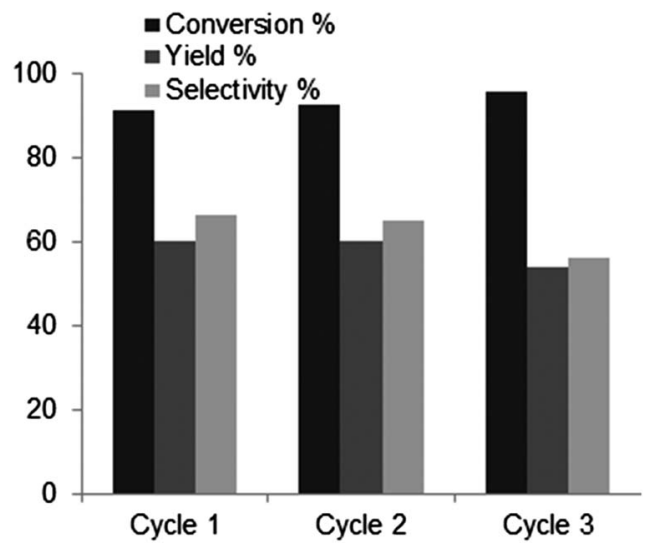

Fig. 10 Results of the recycling experiments of B-TUD-1 25 in biphasic conditions $\left(190{ }^{\circ} \mathrm{C}, 40 \mathrm{~min}, 30 \mathrm{wt} \%\right.$ fructose, 10 wt\% M-TUD-1, toluene/water 3/1), conversion of fructose (\%), yield of HMF, selectivity to HMF (\%).

different boron containing zeolites, ${ }^{\mathbf{4 5 , 4 9}}$ both the conversion of tetrahedral to trigonal boron, as well as the progressive cleavage of the $\mathrm{Si}-\mathrm{O}-\mathrm{B}$ bridges, leading to a partial deboronation.

This observed leaching, questions the character of the catalysis, heterogeneous ensured by the solid catalyst, or 
A)
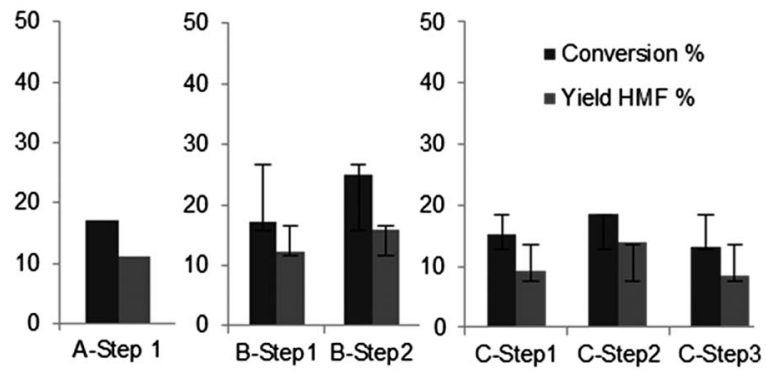

B) 100

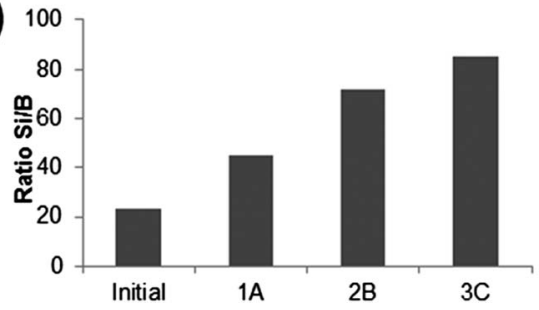

Fig. 11 (A) Results of the recycling experiments in aqueous phase (A, 1 reaction cycle; $B, 2$ reaction cycles/ 1 recycling step; $C, 3$ reaction cycles/2 recycling steps; $160{ }^{\circ} \mathrm{C} ; 1 \mathrm{~h}, 30 \mathrm{wt} \%$ fructose, 10 wt\% B-TUD-1 25), conversion of fructose (\%), yield of HMF; $(B)$ ratio Si/B measured by elemental analysis after one (1A), two $(2 \mathrm{~B})$, or three $(3 \mathrm{C})$ reactions.

Table 3 Porosity measurements of the used B-TUD-1 catalysts after the HMF synthesis or Prins reaction

\begin{tabular}{lllllll}
\hline Treatment & HMF & \multicolumn{4}{c}{ Prins } \\
\hline Si/B (initiaI) & $50 / 1$ & $25 / 1$ & $10 / 1$ & $25 / 1$ & $10 / 1$ \\
$S_{\text {BET }}\left(\mathrm{m}^{2} \mathrm{~g}^{-1}\right)$ & 375 & 434 & 503 & 530 & 599 \\
Pore diameter $D_{\text {pore }}(\mathrm{nm})$ & 8.8 & 5.5 & 5.5 & 5.1 & 5.0 \\
Total volume pore $V_{\text {pore }}\left(\mathrm{mL} \mathrm{g}^{-1}\right)$ & 0.825 & 0.599 & 0.696 & 0.675 & 0.748 \\
Micropore volume $V_{\text {micro }}\left(\mathrm{mL} \mathrm{g}^{-1}\right)$ & n.d $^{a}$ & 0.137 & 0.003 & 0.030 & 0.028
\end{tabular}

${ }^{a}$ Not determined because not measurable.

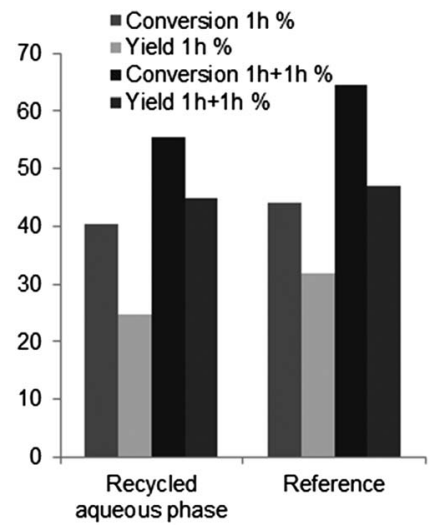

Fig. 12 Results of the recycling experiment of the aqueous phase of the reaction medium $\left(175{ }^{\circ} \mathrm{C}, 1 \mathrm{~h},+1 \mathrm{~h}\right.$ after filtration or $+1 \mathrm{~h}$ without filtration for the reference, $30 \mathrm{wt} \%$ fructose, $10 \mathrm{wt} \%$ B-TUD-1 25), conversion of fructose (\%), yield of $\operatorname{HMF}(\%)$

homogeneous ensured by the released boric acid. To clarify this point, a recycling experiment of the aqueous phase of the reaction was carried out (Fig. 12). The catalyst was filtered off after one hour and the reaction was continued with the remaining aqueous phase for an extra hour. In parallel, a reference sample was running, where the catalyst was not removed.

The reaction was shown to continue despite the removal of B-TUD-1. Both conversion and yield continued to increase. Moreover, very similar results were obtained with the solid catalyst or after removal of the catalyst (Fig. 12). Our conclusion is that the released boric acid catalyses the HMF formation. Finally, a last experiment (conditions biphasic, $190^{\circ} \mathrm{C}, 40 \mathrm{~min}$ ), conducted with a small concentration of boric acid (4 wt\%) led to similar results ( $89 \%$ conversion, $59 \%$ HMF yield) as the ones observed with the solid catalysts $(91 \%$ conversion, $60 \% \mathrm{HMF}$ yield), thus confirming this assertion.

This result with B-TUD-1 can be compared to the stability of Al-TUD-1 under similar conditions. Lima et al. ${ }^{60}$ showed a good recyclability of Al-TUD-1 under similar reaction conditions. Moreover, our measurement of the ${ }^{27} \mathrm{Al}$ MAS NMR after reaction showed identical spectra to the original calcined sample. This difference in stability can be explained by a smaller size of the boron and its greater dynamic reactivity in the silica framework.

\section{Performance test in organic media: Prins cyclisation}

The catalyst performance was also tested in the Prins reaction $^{72-74}$ (Scheme 2), an important C-C bond forming reaction catalysed by acids. ${ }^{75,76}$

This intramolecular cyclisation of citronellal, a renewable product, is an essential step in the Takasago synthesis of menthol. ${ }^{77}$ Industrially, the reaction is catalysed by stoichiometric amounts of solid $\mathrm{ZnBr}_{2}$ in benzene. ${ }^{78}$ Recently, the implementation of alternative processes using heterogeneous catalysts has attracted considerable attention. ${ }^{11,58,79-89}$ The Prins reaction was carried out with the different B-TUD-1 (50, 25 and 10) catalysts as well as with Al-TUD-1 25 as a reference (Scheme 3).

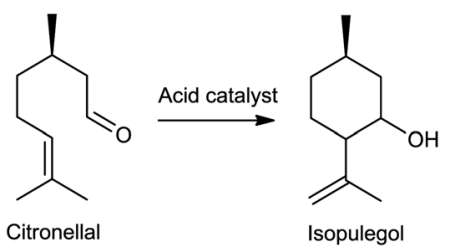

Scheme 2 Intramolecular Prins cyclisation of citronellal.

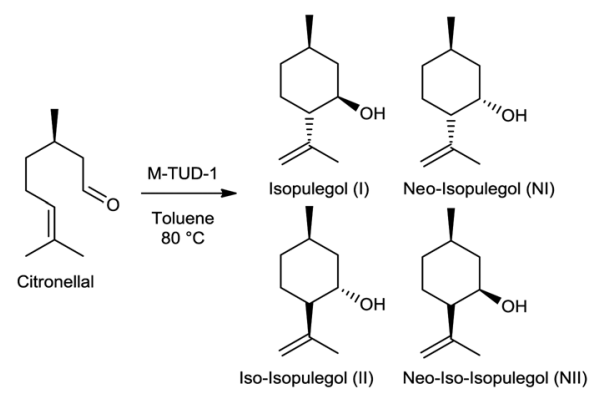

Scheme 3 Cyclisation of citronellal to isopulegol and its isomers catalysed by MTUD-1 material. 
A)

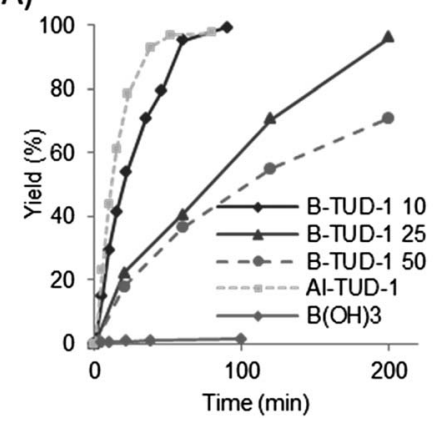

B)

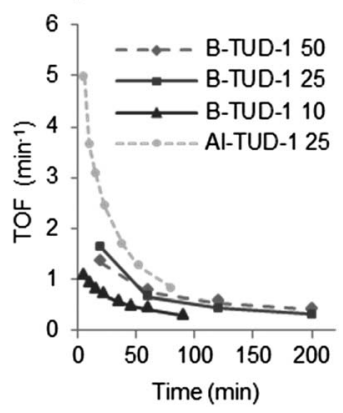

Fig. 13 (A) Evolution of the yield of isopulegol formed during the Prins cyclisation catalysed by various B- and Al-TUD-1 catalyst; (B) evolution of the TOF of the catalysts during the reaction (in mol converted product per mol B or Al per min).

The obtained activity of the B-TUD-1 catalysts was quite high (Fig. 13) and was increasing with the amount of incorporated boron (thus with a decreasing $\mathrm{Si} / \mathrm{B}$ ratio). It should be noticed that the experiments were carried out with industrial grade citronellal containing around 5\% isopulegol. As it has previously been shown, the presence of isopulegol partially inhibits the conversion of citronellal. Higher activities can be expected starting from optically pure citronellal. ${ }^{58}$

We could observe full conversion after one hour for the B-TUD110 . This result is very close to the conversion that we obtained via Al-TUD-1 (full conversion after approximately 50 minutes). Full conversion was reached after four hours for B-TUD-1 25, $80 \%$ conversion was obtained after $6 \mathrm{~h}$ with B-TUD-1 50. Despite an apparent lower activity of the latter two catalysts, the comparison of their turn over frequencies (TOF, Fig. 13B) showed their activity per active site to be actually higher than for B-TUD-1 10 .

These results are similar to the results with Zr-TUD-1 100. We can also compare this performance to other examples of zeolite catalysts for this reaction. Similar performance was observed under the exact same conditions with Al-MSU-50 (ref. 83) (88.6\% conversion after 30 minutes, and $96.7 \%$ after 60 minutes), whereas $\mathrm{Zr}$-incorporated $\mathrm{MOF}^{89}$ only presented a full conversion after a minimum of $4 \mathrm{~h}$ at $100{ }^{\circ} \mathrm{C}$ for a citronellal/Zr ratio of 10 (in our conditions, with B-TUD-1 10, citronellal/B ratio of 9 , with B-TUD-1 25, citronellal/B ratio of 21). Our catalyst thus presents an interesting activity for the Prins cyclisation of citronellal. The product selectivity to isopulegol (all diastereoisomers) for all the catalysts appeared excellent ( $\geq 95 \%$, Table 4$)$. The observed diastereoselectivity to isopulegol ( $v s$. its other diastereoisomers) is around 63/37 for all B-containing TUD-1 catalysts (Table 4). This result is close to the measured diastereoselectivity of

Table 4 Conversion, selectivity and diastereoselectivity for M-TUD-1 catalysts in the Prins cyclisation of citronellal

\begin{tabular}{lrlll}
\hline Catalyst & Time & $\begin{array}{l}\text { Conversion } \\
(\%)\end{array}$ & $\begin{array}{l}\text { Selectivity } \\
(\%)\end{array}$ & $\begin{array}{l}\text { Diastereoselectivity } \\
\text { I/MI/II/NII (\%) }\end{array}$ \\
\hline Al-TUD-1 25 & 60 & 98 & 98 & $66.3 / 22.6 / 7.05 / 0.05$ \\
B-TUD-1 10 & 60 & 97 & 98 & $63.2 / 30.1 / 5.1 / 1.6$ \\
B-TUD-1 25 & 240 & 96 & 95 & $63.2 / 30.1 / 4.8 / 1.8$ \\
B-TUD-1 50 & 360 & 81 & 98 & $62.7 / 30.2 / 5.1 / 2.0$
\end{tabular}

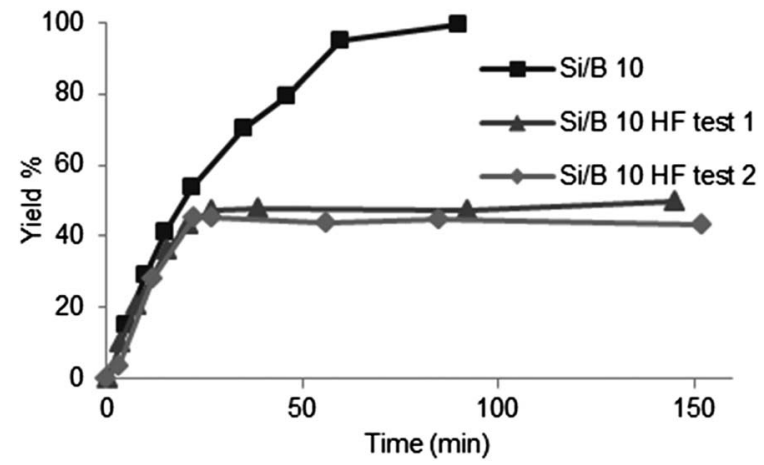

Fig. 14 Hot filtration test on B-TUD-1 10 during the Prins cyclisation of citronellal; catalyst filtered after 20 minutes; $80^{\circ} \mathrm{C}$.

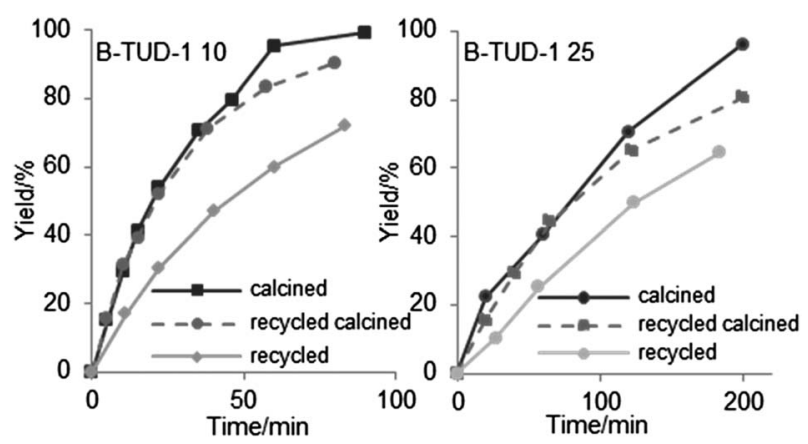

Fig. 15 Results of the recycling experiments with or without intermediate calcination of the B-TUD-1 25 and 10 catalysts, yield of isopulegol (\%).

Al-TUD-1 25 (66/34) and to the values described in literature for Zr-TUD-1 (average 65/35). ${ }^{58}$ The reduced pore diameter of B-TUD-1 10 does not influence this ratio. ${ }^{58}$

A liquid ${ }^{11} \mathrm{~B}$ NMR of the reaction medium after filtration of the catalyst did not show the presence of boron compounds, indicating the absence of leaching. Furthermore a porosity measurement of the catalysts after reaction and calcination showed very similar results (Table 3) to the initials catalysts (Table 1). Finally, a hot filtration test was carried out. After $20 \mathrm{~min}$, the reaction medium is sampled, immediately filtered, and left again at $80^{\circ} \mathrm{C}$. This operation is performed on a hot sample to prevent any possible precipitation of diluted compounds. ${ }^{90}$ After the removal of the solid catalyst, the reaction clearly stopped (Fig. 14), proving the heterogeneous nature of the catalytic activity.

Recycling steps were realised with the catalysts B-TUD-1 10 and 25 , with or without calcination before the recycling reaction (Fig. 15). Very similar results were obtained with the calcined recycled catalysts, whereas we could observe a net decrease of the activity of the non-calcined samples, probably partially inhibited by the product remaining on the catalyst as described earlier..$^{58}$

\section{Conclusions}

We successfully obtained and characterized a new, easy to prepare, three-dimensional and mesoporous acidic B-TUD-1 catalyst. We verified the mesoporous and amorphous character of the material as well as the incorporation of the boron into the 
framework even at low $\mathrm{Si} / \mathrm{B}$ ratio. We also characterized the mixed acidity of the material (Brønsted and Lewis acid sites) as well as the different possible structures of the incorporated boron (trigonal and tetrahedral) and their dynamic equilibrium. Catalytic tests showed the efficiency of this material for the catalysis of different sustainable reactions. However, in the case of HMF synthesis, the acidic aqueous reaction conditions caused boron leakage and a change of the structure of the material was observed. On the contrary, B-TUD-1 demonstrated high reactivity as well as reasonable recyclability for the Prins cyclisation of citronellal in toluene. B-TUD-1 is there with a promising heterogeneous acid that catalyses reactions under non-aqueous conditions.

\section{Experimental section}

\section{Materials and methods}

All chemicals were purchased from Aldrich, Janssen or Acros. For the catalysis experiments, the anhydrous solvents and solids were used as received, all other liquids were dried and distilled prior use. M-TUD-1 catalysts were activated in the presence of air at up to $600{ }^{\circ} \mathrm{C}$ at a ramp of $1{ }^{\circ} \mathrm{C} \mathrm{min}{ }^{-1}$ and heated at $600{ }^{\circ} \mathrm{C}$ for $10 \mathrm{~h}$. The experiments were performed in dried glassware and under $\mathrm{N}_{2}$ atmosphere.

\section{Catalyst preparation}

General protocol. Dry isopropanol and ethanol were added to a plastic flask (washed with acetone and placed $30 \mathrm{~min}$ in an oven at $60{ }^{\circ} \mathrm{C}$ ) and the flask was closed. $\mathrm{M}(i \mathrm{PrO})_{3}$ (aluminium or boron isopropoxide) was ground (in case of $\mathrm{Al}$; $\mathrm{B}$ is liquid) before addition to the isopropanol/ethanol mix. Then TEOS (tetraethyl orthosilicate) was added. This mixture was stirred $20 \mathrm{~min}$, resulting in a milky solution. TEA (triethanolamine) was weighed and diluted with water. The TEA/water mix was added dropwise over a period of $25 \mathrm{~min}$, whilst stirring, then the mixture was stirred an additional $20 \mathrm{~min}$. This resulted in a milky/glassy white gel. TEAOH (tetraethylammonium hydroxide solution 35\%) was then added dropwise over a period of $30 \mathrm{~min}$. This yielded a gel with a molar ratio of $\mathrm{SiO}_{2} / x \mathrm{M}(i \mathrm{PrO})_{3} /(0.3-0.5) \mathrm{TEAOH} /(0.7-1.1)$ TEA/(10-20) $\mathrm{H}_{2} \mathrm{O}$. After 30-45 min extra stirring, the gel formed was transferred to a porcelain bowl and was allowed to dry at room temperature overnight. The porcelain bowl was placed in an oven at $98{ }^{\circ} \mathrm{C}$ for $24 \mathrm{~h}$ (drying step). It turned into a yellow, transparent solid. This solid was ground, then transferred in Teflon lined steel autoclaves, and placed in an oven at $180{ }^{\circ} \mathrm{C}$ for $6 \mathrm{~h}$ (hydrothermal treatment). After this hydrothermal treatment, the material was transferred again into the porcelain bowl and placed in the calcination oven. The following program was applied (calcination step): heating at $1{ }^{\circ} \mathrm{C} \min ^{-1}$ until $600{ }^{\circ} \mathrm{C}$, hold at this temperature for $10 \mathrm{~h}$, then cooled down to $50{ }^{\circ} \mathrm{C}$ at a rate of $1{ }^{\circ} \mathrm{C} \min ^{-1}$. The M-TUD-1 was recovered as a white solid.

\section{Catalyst characterization}

The volumetric nitrogen adsorption was realised on a Quantachrome Autosorb-6B at $77 \mathrm{~K}$. Prior to the physisorption experiments, samples were degassed at $250{ }^{\circ} \mathrm{C}$ for $16 \mathrm{~h}$.
Powder XRD patterns were obtained on a Philips PW 1840 diffractometer equipped with a graphite monochromator using $\mathrm{CuK} \alpha$ radiation. The powder XRD patterns at small angles were obtained with a Bruker D8 Discover X-ray diffractometer equipped with the 2-dimensional Hi-Star Area Detector and Cross Coupled Göbel Mirrors. The measurements were performed in transmission mode at room temperature using monochromatic $\mathrm{CuK} \alpha 1$ radiation and a sample to detector face of $30 \mathrm{~cm}$.

The elemental analysis of the materials was carried out using an ICP-OES 4300DV plasma emission spectrometer (Perkin Elmer, United States), enabling simultaneous recording of the full emission spectrum of the sample in the range from 166.25 to $847 \mathrm{~nm}$ with the help of a Charge Injection Device (CID). The spectrometer was equipped with a cyclonic spray chamber with concentric nebulizer. A double system of observation of plasma was used (axial and radial). Approximately 10-40 mg sample was weighed, and transported into a thoroughly rinsed Teflon vessel. All samples are dissolved in an aqua regia acid mixture containing $1.2 \mathrm{~mL}$ concentrated hydrochloric acid (36\% v/v), $0.4 \mathrm{~mL}$ concentrated nitric acid $(69 \% \mathrm{v} / \mathrm{v})$ plus $0.4 \mathrm{~mL}$ concentrated hydrofluoric acid $(40 \% \mathrm{v} / \mathrm{v})$.

Temperature-programmed desorption (TPD) of ammonia was carried out on a Micromeritics TPR/TPD 2920 equipped with a thermal conductivity detector (TCD). The sample $(30 \mathrm{mg})$ was pre-treated at $600{ }^{\circ} \mathrm{C}$ to remove volatile components. Prior to the TPD measurements the samples were degassed at $250{ }^{\circ} \mathrm{C}$ (after ramping from room temperature at a ramp rate of $10{ }^{\circ} \mathrm{C}$ $\min ^{-1}$ ) for $1 \mathrm{~h}$ then saturated with ammonia gas at $100{ }^{\circ} \mathrm{C}$ for 30 min at a flow of $20 \mathrm{~cm}^{3} \mathrm{~min}^{-1}$. After a purge of ammonia by helium for $30 \mathrm{~min}$ at a flow of $10 \mathrm{~cm}^{3} \mathrm{~min}^{-1}$ at $100{ }^{\circ} \mathrm{C}$, desorption of $\mathrm{NH}_{3}$ was monitored in the range between 100 and $600{ }^{\circ} \mathrm{C}$ at a ramp rate of $10{ }^{\circ} \mathrm{C} \mathrm{min}^{-1}$.

The FT-IR spectra were measured on a Perkin Elmer Spectrum ONE instrument. A KBr wafer was prepared containing a particular amount of the calcined sample that allowed for a transmission of minimally $50 \%(<1 \mathrm{mg})$. The spectrum was taken over a range of $450-4000 \mathrm{~cm}^{-1}$ with a resolution of $1 \mathrm{~cm}^{-1}$.

Transmission electron microscopy was performed by using a Philips CM30T electron microscope with a LaB6 filament as source of electrons operated at $300 \mathrm{kV}$.

The MAS NMR was recorded on a Bruker Avance-400 Spectrometer with a $4 \mathrm{~mm}$ zirconium rotor sample holder spinning at $10 \mathrm{kHz}$. The ${ }^{11} \mathrm{~B} /{ }^{27} \mathrm{Al}$ MAS NMR was measured at a frequency of $128.31 / 104.20 \mathrm{MHz}$ with a spectral width of $25 / 100 \mathrm{kHz}$, acquisition time of $0.05 \mathrm{~s} / 0.08 \mathrm{~s}$, and acquisition delay $1 \mathrm{~s}$, the total number of scans was $2000 / 4000$. Liquid ${ }^{11}$ B NMR spectra were recorded with a Bruker Avance 400 spectrometer with chemical shifts $(\delta)$ reported in ppm downfield with $\mathrm{B}(\mathrm{OH})_{3}$ $0.1 \mathrm{M}$ in $\mathrm{D}_{2} \mathrm{O}$.

\section{HMF synthesis}

General protocol. $600 \mathrm{mg}$ of fructose and $200 \mathrm{mg}$ of M-TUD-1 were weighed and filled in an Ace ${ }^{\circledR}$ pressure $15 \mathrm{~mL}$-glass tube. The solution was completed to $2 \mathrm{~mL}$ by adding demi-water, then $6 \mathrm{~mL}$ of toluene was added in the case of the biphasic 
experiments. The solution was placed in an oil bath at the desired temperature. After the defined time of reaction, the tube was removed from the oil bath and allowed to cool down to room temperature (in $5 \mathrm{~min}$ approx.). In the case of biphasic reactions, the two phases were allowed to separate for a few minutes. $100 \mu \mathrm{L}$ of the organic phase was then sampled, derivatised and analyzed by GC (replicated). The aqueous phase was diluted 5 times by adding $8 \mathrm{~mL} 0.005 \mathrm{M} \mathrm{H}_{2} \mathrm{SO}_{4} .2 \mathrm{~mL}$ of this diluted solution was transferred into an Eppendorf tube, centrifuged and the supernatant analyzed by HPLC.

Recycling step (recycled catalyst). Just after reaction and cooling ( $c f$. protocol above), the Ace ${ }^{\circledR}$ tubes were centrifuged 10 min at $1800 \mathrm{rpm}$. The recovered pellets (humins and catalyst) were placed in an oven and calcined at $600{ }^{\circ} \mathrm{C}$ for $6 \mathrm{~h}$, then used in a recycling step (same protocol followed).

Recycling step (recycled solution). Just after reaction and cooling ( $c f$. protocol above), the Ace ${ }^{\circledR}$ tubes were centrifuged 10 min at $1800 \mathrm{rpm}$. The supernatant was placed in the same conditions as a classical reaction.

HMF synthesis: HPLC analysis (aqueous phase). Samples were diluted by a factor 10 or 20 with an aqueous solution of $\mathrm{H}_{2} \mathrm{SO}_{4}$ at $0.005 \mathrm{M} .10 \mu \mathrm{L}$ of the diluted samples were measured by HPLC. The used eluent was an aqueous solution of $\mathrm{H}_{2} \mathrm{SO}_{4}$ at $0.005 \mathrm{M}$. The method lasted $35 \mathrm{~min}$ with a flow rate of $0.8 \mathrm{~mL}$ $\mathrm{min}^{-1}$. Both UV (for HMF and furaldehyde, Fal) and RI (for HMF, fructose, levulinic acid, LA, formic acid, FA, and Fal) detections were used. Retention times: fructose: $7.3 \mathrm{~min}, \mathrm{FA}: 10.3$ min, LA: 11.5 min, HMF: 21.7 min, Fal: 32.6 min.

HMF synthesis: derivatisation and GC analysis (organic phase). $100 \mu \mathrm{L}$ of the toluene phase was sampled. $50 \mu \mathrm{L}$ of the IS solution (hydroquinone, $20 \mathrm{mg}$ in $10 \mathrm{~mL}, 2 \mathrm{~g} \mathrm{~L}^{-1}$ ) was added. $150 \mu \mathrm{L}$ of BSTFA (N,O-bis-trimethylsilyltrifluoroacetamide) reagent was finally added. After agitation $(5 \mathrm{~min})$ the mixture was measured in GC. The method lasted $15 \mathrm{~min}$. GC method (Varian FactorFour VF-1ms column): carrier gas: He; detector temperature: $330{ }^{\circ} \mathrm{C}$; injector temperature: $300{ }^{\circ} \mathrm{C}$; temp. gradient: beginning at $100^{\circ} \mathrm{C}$ hold for $4.2 \mathrm{~min}$, then increase of $15^{\circ} \mathrm{C} \mathrm{min}{ }^{-1}$ to $140{ }^{\circ} \mathrm{C}$, of $20^{\circ} \mathrm{C} \mathrm{min}^{-1}$ to $240{ }^{\circ} \mathrm{C}$ and finally of 40 ${ }^{\circ} \mathrm{C} \min ^{-1}$ to $325{ }^{\circ} \mathrm{C}$ (hold $1 \mathrm{~min}$ ); column flow: $1.08 \mathrm{~mL} \mathrm{~min}^{-1}$ (linear velocity $42.2 \mathrm{~cm} \mathrm{~s}^{-1}$ ); split ratio: 20 , Retention times: HMF: $6.0 \mathrm{~min}$, IS: $7.3 \mathrm{~min}$.

\section{Prins reaction}

General protocol (following method reported earlier. ${ }^{11,83}$ ) In a Schlenk flask of $50 \mathrm{~mL}$ (placed in an oven at $70{ }^{\circ} \mathrm{C} \mathrm{o} / \mathrm{n}$ ), $50 \mathrm{mg}$ of catalyst (activated in an oven overnight at $100{ }^{\circ} \mathrm{C}$ ) were introduced. After flushing the atmosphere with $\mathrm{N}_{2}, 5 \mathrm{~g}$ of dry toluene were introduced, $0.1 \mathrm{~mL}$ of triisopropylbenzene (IS) were added and finally $4 \mathrm{mmol}$ of \pm citronellal (industrial grade, containing approx. $5 \%$ isopulegol, $0.725 \mathrm{~mL}$ ). The mixture was then introduced in an oil bath at $80{ }^{\circ} \mathrm{C}$ and stirred under $\mathrm{N}_{2}$. Regularly, samples were withdrawn using a capillary (introduced in the reaction medium via a needle), filtered over a cotton plug (in a Pasteur pipette), diluted and analysed by GC.

GC method. Column: Cyclodex-B; detector temperature: $270{ }^{\circ} \mathrm{C}$; injector temperature: $250{ }^{\circ} \mathrm{C}$; temp. gradient: beginning at $140{ }^{\circ} \mathrm{C}$ hold for $16.0 \mathrm{~min}$, then increased of ${ }^{\circ} \mathrm{C} \min ^{-1}$ to $250{ }^{\circ} \mathrm{C}$ (hold $1 \mathrm{~min}$ ); column flow: $0.87 \mathrm{~mL} \mathrm{~min}^{-1}$ (linear velocity $20.3 \mathrm{~cm} \mathrm{~s}^{-1}$ ); split ratio: 50; total time: $19.20 \mathrm{~min}$. Retention times: \pm citronellal: $12.67 \mathrm{~min}$, isopulegol: 13.45, neo-isopulegol: $13.62 \mathrm{~min}$, iso-isopulegol: $14.77 \mathrm{~min}$, neoiso-isopulegol: $14.90 \mathrm{~min}$, IS: $17.03 \mathrm{~min}$.

Recycling step. The catalysts were recycled after filtration and calcination $\left(600{ }^{\circ} \mathrm{C}, 6 \mathrm{~h}\right)$ or activation $\left(100^{\circ} \mathrm{C}\right.$ overnight $)$ and used following the same protocol.

Hot filtration test. The reaction is started as described above. After 20 minutes the reaction medium is sampled via a dried syringed and immediately filtered through a PTFE syringe filter previously washed with anhydrous toluene at $80{ }^{\circ} \mathrm{C}$. The liquid medium is introduced directly into a Schlenk flask of $50 \mathrm{~mL}$, previously placed overnight in an oven at $70{ }^{\circ} \mathrm{C}$ and flushed with $\mathrm{N}_{2}$, and let at $80^{\circ} \mathrm{C}$. The monitoring of the reaction was realized before and after filtration following the same protocol as describe before.

\section{Acknowledgements}

The authors gratefully acknowledge financial support from BeBasic and Dr Harald Ruijssenaars (Bird Engineering) for fruitful and valuable discussions about this work. The authors would like to acknowledge the TU Delft colleagues for their help in the different analyses: Willy Rook (physisorption), Dr Olav Steinebach (ICP-OES), Dr Patricia Kooyman (TEM), Ben Norder (XRD), Remco van Oosten (GC), Maarten Gorseling (HPLC, FTIR).

\section{Notes and references}

1 J. C. Jansen, Z. Shan, L. Marchese, W. Zhou, N. van der Puil and T. Maschmeyer, Chem. Commun., 2001, 713-714.

2 M. S. Hamdy, PhD thesis, Delft University of Technology, 2005, open access on: http://repository.tudelft.nl/search/ir/? $\mathrm{q}=$ Hamdy\&faculty $=$ \&department $=$ \&type $=$ \&year $=$.

3 S. Telalovic, A. Ramanathan, G. Mul and U. Hanefeld, J. Mater. Chem., 2010, 20, 642-658.

4 Z. Shan, E. Gianotti, J. C. Jansen, J. A. Peters, L. Marchese and T. Maschmeyer, Chem.-Eur. J., 2001, 7, 1437-1443.

5 C. Simons, U. Hanefeld, I. W. C. E. Arends, R. A. Sheldon and T. Maschmeyer, Chem.-Eur. J., 2004, 10, 5829-5835.

6 A. Ramanathan, M. S. Hamdy, U. Hanefeld and T. Maschmeyer, Catal. Lett., 2004, 95, 113-117.

7 M. S. Hamdy, G. Mul, W. Wei, R. Anand, U. Hanefeld, J. C. Jansen and J. A. Moulijn, Catal. Today, 2005, 110, 264271.

8 M. S. Hamdy, A. Ramanathan, T. Maschmeyer, U. Hanefeld and J. C. Jansen, Chem.-Eur. J., 2006, 12, 1782-1789.

9 A. Ramanathan, D. Klomp, J. A. Peters and U. Hanefeld, J. Mol. Catal. A: Chem., 2006, 260, 62-69.

10 A. Ramanathan, M. S. Hamdy, R. Parton, T. Maschmeyer, J. C. Jansen and U. Hanefeld, Appl. Catal., A, 2009, 355, 7882.

11 S. Telalović, A. Ramanathan, J. F. Ng, R. Maheswari, C. Kwakernaak, F. Soulimani, H. C. Brouwer, G. K. Chuah, 
B. M. Weckhuysen and U. Hanefeld, Chem.-Eur. J., 2011, 17, 2077-2088.

12 C. C. Aquino, H. O. Pastore, A. F. Masters and T. Maschmeyer, ChemCatChem, 2011, 3, 1759-1762.

13 G. Imran, M. P. Pachamuthu, R. Maheswari, A. Ramanathan and S. J. Sardhar Basha, J. Porous Mater., 2012, 19, 677682.

14 L. Li, T. I. Koranyi, B. F. Sels and P. P. Pescarmona, Green Chem., 2012, 14, 1611-1619.

15 M. M. Antunes, S. Lima, M. Pillinger and A. A. Valente, Molecules, 2012, 17, 3690-3707.

16 Z. Guo, C. Zhou, S. Hu, Y. Chen, X. Jia, R. Lau and Y. Yang, Appl. Catal., A, 2012, 419-420, 194-202.

17 S. Haddoum, I. Fechete, B. Donnio, F. Garin, D. Lutic and C. E. Chitour, Catal. Commun., 2012, 27, 141-147.

18 B. Wang, T. P. Ang and A. Borgna, Sci. Adv. Mater., 2011, 3, 1004-1010.

19 B. Wang, T. P. Ang and A. Borgna, Microporous Mesoporous Mater., 2012, 158, 99-107.

20 M. S. Hamdy and G. Mul, Catal. Sci. Technol., 2012, 2, 18941900.

21 N. Gargiulo, F. Pepe and D. Caputo, J. Colloid Interface Sci., 2012, 367, 348-354.

22 S. Lima, M. M. Antunes, A. Fernandes, M. Pillinger, M. F. Ribeiro and A. A. Valente, Appl. Catal., A, 2010, 388, 141-148.

23 D. Liu, X.-Y. Quek, S. Hu, L. Li, H. M. Lim and Y. Yang, Catal. Today, 2009, 147, S51-S57.

24 X.-Y. Quek, D. Liu, W. N. E. Cheo, H. Wang, Y. Chen and Y. Yang, Appl. Catal., B, 2010, 95, 374-382.

25 K. Parkhomenko, A. Tyunyaev, L. M. M. Tejada, A. Dedov, A. Loktev, I. Moiseev and A. C. Roger, IOP Conf. Ser.: Mater. Sci. Eng., 2011, 19, 012008.

26 C. Qi, J. Huang, S. Bao, H. Su, T. Akita and M. Haruta, J. Catal., 2011, 281, 12-20.

27 S. Mandal, A. SinhaMahapatra, B. Rakesh, R. Kumar, A. Panda and B. Chowdhury, Catal. Commun., 2011, 12, 734-738.

28 J. Zhou, Z. Hua, J. Shi, Q. He, L. Guo and M. Ruan, Chem.Eur. J., 2009, 15, 12949-12954.

29 B. Karmakar, A. Sinhamahapatra, A. B. Panda, J. Banerji and B. Chowdhury, Appl. Catal., A, 2011, 392, 111-117.

30 L. Deloux and M. Srebnik, Chem. Rev., 1993, 93, 763-784.

31 T. Müller, K. Djanashvili, I. W. C. E. Arends, J. A. Peters and U. Hanefeld, Chem. Commun., 2013, 49, 361-363.

32 T. A. Houston, B. L. Wilkinson and J. T. Blanchfield, Org. Lett., 2004, 6, 679-681.

33 N. Maraš and M. Kočevar, Helv. Chim. Acta, 2011, 94, 18601874.

34 G. L. O'Connor and H. R. Nace, J. Am. Chem. Soc., 1955, 77, 1578-1581.

35 J. ten Dam and U. Hanefeld, ChemSusChem, 2011, 4, 10171034.

36 J. ten Dam, F. Kapteijn, K. Djanashvili and U. Hanefeld, Catal. Commun., 2011, 13, 1-5.

37 T. S. Hansen, J. Mielby and A. Riisager, Green Chem., 2011, 13, 109-114.
38 S. Kallus, J. Patarin, P. Caullet and A. C. Faust, Microporous Mater., 1997, 10, 181-188.

39 H. Koller, C. Fild and R. F. Lobo, Microporous Mesoporous Mater., 2005, 79, 215-224.

40 I. Lezcano-Gonzalez, A. Vidal-Moya, M. Boronat, T. Blasco and A. Corma, Phys. Chem. Chem. Phys., 2010, 12, 63966403.

41 T. D. Conesa, J. M. Campelo, D. Luna, J. M. Marinas and A. A. Romero, Appl. Catal., B, 2007, 70, 567-576.

42 S. Liu, H. He, Z. Luan and J. Klinowski, J. Chem. Soc., Faraday Trans., 1996, 92, 2011-2015.

43 I. Eswaramoorthi and A. K. Dalai, Microporous Mesoporous Mater., 2006, 93, 1-11.

44 T. D. Conesa, J. M. Hidalgo, R. Luque, J. M. Campelo and A. A. Romero, Appl. Catal., A, 2006, 299, 224-234.

45 R. de Ruiter, A. P. M. Kentgens, J. Grootendorst, J. C. Jansen and H. van Bekkum, Zeolites, 1993, 13, 128-138.

46 M. Adjdir, T. Ali-Dahmane and P. G. Weidler, C. R. Chim., 2009, 12, 793-800.

47 J. Zhang, M. Liu, C. Song and X. Guo, Microporous Mesoporous Mater., 2011, 139, 31-37.

48 A. Sayari, C. Danumah and I. L. Moudrakovski, Chem. Mater., 1995, 7, 813-815.

49 C. Fild, D. F. Shantz, R. F. Lobo and H. Koller, Phys. Chem. Chem. Phys., 2000, 2, 3091-3098.

50 M. G. Dekamin, Z. Mokhtari and Z. Karimi, Sci. Iran., 2011, 18, 1356-1364.

51 J. K. Puri, R. Singh and V. K. Chahal, Chem. Soc. Rev., 2011, 40, 1791-1840.

52 G. García, M. Falco, P. Crespo, S. Cabrera and U. Sedran, Catal. Today, 2011, 166, 60-66.

53 S. Cabrera, J. El Haskouri, C. Guillem, J. Latorre, A. BeltránPorter, D. Beltrán-Porter, M. D. Marcos and P. Amorós, Solid State Sci., 2000, 2, 405-420.

54 A. Sonoda, N. Takagi, K. Ooi and T. Hirotsu, Bull. Chem. Soc. Jpn., 1998, 71, 161-166.

55 M. Bonzcek and H. Follner, Monatsh. Chem., 1976, 107, 283288.

56 D. J. Kim, Y. Hong, S. H. Kim, K. M. Lee, S.-d. Mun, S. Yoon, J. Lee, Y. Do and Y. Kim, Inorg. Chim. Acta, 2011, 378, 311314.

57 B. Samran, T. J. White and S. Wongkasemjit, J. Porous Mater., 2011, 18, 167-175.

58 A. Ramanathan, M. C. Castro Villalobos, C. Kwakernaak, S. Telalovic and U. Hanefeld, Chem.-Eur. J., 2008, 14, 961972.

59 A. Ramanathan, R. Maheswari and U. Hanefeld, J. Catal., 2006, 242, 82-91.

60 S. Lima, M. M. Antunes, A. Fernandes, M. Pillinger, M. F. Ribeiro and A. A. Valente, Molecules, 2010, 15, 38633877.

61 S. Telalović, S. K. Karmee, A. Ramanathan and U. Hanefeld, J. Mol. Catal. A: Chem., 2013, 368-369, 88-94.

62 A. A. Rosatella, S. P. Simeonov, R. F. M. Frade and C. A. M. Afonso, Green Chem., 2011, 13, 754-794.

63 Y. B. Yi, J. L. Lee, Y. H. Choi, S. M. Park and C. H. Chung, Environ. Chem. Lett., 2012, 10, 13-19. 
64 Y. J. Pagan-Torres, T. Wang, J. M. Gallo, B. H. Shanks and J. A. Dumesic, ACS Catal., 2012, 2, 930-934.

65 H. Jadhav, E. Taarning, C. M. Pedersen and M. Bols, Tetrahedron Lett., 2012, 53, 983-985.

66 X. Guo, Q. Cao, Y. Jiang, J. Guan, X. Wang and X. Mu, Carbohydr. Res., 2012, 351, 35-41.

67 A. J. Crisci, M. H. Tucker, M.-Y. Lee, S. G. Jang, J. A. Dumesic and S. L. Scott, ACS Catal., 2011, 1, 719-728.

68 V. Degirmenci, E. A. Pidko, P. C. M. M. Magusin and E. J. M. Hensen, ChemCatChem, 2011, 3, 969-972.

69 J. Jae, G. A. Tompsett, A. J. Foster, K. D. Hammond, S. M. Auerbach, R. F. Lobo and G. W. Huber, J. Catal., 2011, 279, 257-268.

70 V. V. Ordomsky, J. van der Schaaf, J. C. Schouten and T. A. Nijhuis, J. Catal., 2012, 287, 68-75.

71 T. Ståhlberg, S. Rodriguez-Rodriguez, P. Fristrup and A. Riisager, Chem.-Eur. J., 2011, 17, 1456-1464.

72 H. J. Prins, Chem. Weekbl., 1917, 14, 627-630.

73 H. J. Prins, Chem. Weekbl., 1917, 14, 932-939.

74 H. J. Prins, Chem. Weekbl., 1919, 16, 1072-1073.

75 I. M. Pastor and M. Yus, Curr. Org. Chem., 2007, 11, 925-957.

76 I. M. Pastor and M. Yus, Curr. Org. Chem., 2012, 16, 12771312.

77 R. Noyori, Adv. Synth. Catal., 2003, 345, 15-32.

78 Y. Nakatani and K. Kawashima, Synthesis, 1978, 147-148.
79 M. Fuentes, J. Magraner, C. De Las Pozas, R. RoqueMalherbe, J. P. Pariente and A. Corma, Appl. Catal., 1989, 47, 367-374.

80 A. Corma and M. Renz, Chem. Commun., 2004, 550-551.

81 F. Iosif, S. Coman, V. Parvulescu, P. Grange, S. Delsarte, D. D. Vos and P. Jacobs, Chem. Commun., 2004, 1292-1293.

82 D.-L. Shieh, C.-C. Tsai and A.-N. Ko, React. Kinet. Catal. Lett., 2003, 79, 381-389.

83 Z. Yongzhong, N. Yuntong, S. Jaenicke and G.-K. Chuah, J. Catal., 2005, 229, 404-413.

84 Y. Nie, G.-K. Chuah and S. Jaenicke, Chem. Commun., 2006, 790-792.

85 P. Mertens, F. Verpoort, A.-N. Parvulescu and D. De Vos, J. Catal., 2006, 243, 7-13.

86 A. F. Trasarti, A. J. Marchi and C. R. Apesteguía, J. Catal., 2007, 247, 155-165.

87 Y. Nie, S. Jaenicke and G.-K. Chuah, Chem.-Eur. J., 2009, 15, 1991-1999.

88 F. Neaţu, S. Coman, V. Pârvulescu, G. Poncelet, D. De Vos and P. Jacobs, Top. Catal., 2009, 52, 1292-1300.

89 F. Vermoortele, M. Vandichel, B. Van de Voorde, R. Ameloot, M. Waroquier, V. Van Speybroeck and D. E. De Vos, Angew. Chem., Int. Ed., 2012, 51, 4887-4890.

90 R. A. Sheldon, M. Wallau, I. W. C. E. Arends and U. Schuchardt, Acc. Chem. Res., 1998, 31, 485-493. 